\title{
Preface to the special issue on the ecological- hydrological processes in the Heihe River Basin: Integrated research on observation, modeling and data analysis
}

\section{SONG Changqing}

1. State Key Laboratory of Earth Surface Processes and Resource Ecology, Beijing Normal University, Beijing 100875, China;

2. Key Laboratory of Environmental Change and Natural Disaster, Beijing Normal University, Beijing 100875, China;

3. Faculty of Geographical Science, Beijing Normal University, Beijing 100875, China

Research on ecological-hydrological processes in arid/semiarid environments mainly focuses on the following aspects: 1) evolution of the current environments, 2) impacts of human activities and climate change, and 3) sustainable development. In the last decades, with the support of China's top science and research agencies/institutes (e.g., Ministry of Science and Technology, MOST; National Science Foundation China, NSFC; Chinese Academy of Science, CAS), multiple integrated research projects that aim to address the above issues have been initiated from both engineering and scientific perspectives. For example, supported by the NSFC's "China's Western Region Environment and Ecology Science Research Project", in China's northwest arid region, Loess Plateau region and the southwest karst region, four key research themes have been proposed: 1) evolution and development of China's western environment, 2) water cycle and sustainable use of water resources, 3) ecosystem sustainability, and 4) the impact of major constructions/projects on the environment. In addition, "Heihe River Basin Integrated Water Resources Management Research Project" has been the key research project supported by the CAS, which aims to improve water use efficiency, sustain the oasis ecosystem, develop the integrated irrigation water technology, improve water resources management, protect wetland and help with the river basin water management and decision making.

Received: 2019-01-10 Accepted: 2019-03-21

Foundation: National Key R\&D Program of China, No.2017YFA0604704, No.2017YFB0504102; National Natural Science Foundation of China, No.41771537

Author: Song Changqing, Professor, specialized in geographical paradigms and regional integration. E-mail: songcq@bnu.edu.cn 
This special issue of the Journal of Geographical Sciences presents the latest results of the Heihe River Basin (HRB) watershed characteristics and processes research conducted over a decade. Watershed science and function has become a frontier scientific focus area across disciplinaries and communities (Song et al., 2017). The HRB is known as an ideal study area because of its diverse landscapes and unique characteristics in land surface processes. The HRB watershed science research has started since 2007 under China's first and by far the largest watershed research project "Integrated research on the eco-hydrological process of the Heihe River Basin" project supported by the NSFC. During two intensive observation and experiment periods (WATER, Li et al., 2009 and HiWATER, Li et al., 2013), a comprehensive observatory network has been established including hydrometeorological observatory, eco-hydrological wireless sensor network, and satellite remote sensing (Liu et al., 2018). High quality hydrometeorology, ecology, geophysics and cryosphere datasets have been collected and released to the public after rigorous data processing and quality control (Li et al., 2017). A series of scientific questions have also been addresses through the project (Li et al., 2018), e.g., hydrological-ecological processes, data-model integration, and water-energy-food nexus.

The HRB study was envisioned and organized as a state key project over its eleven-year executive period, which included close corporation of multi-institutional teams, building a comprehensive data platform of survey-observation data and supporting information, and conducting applied research for developing numerical methods and models to guide and constrain the water resources and ecosystem functions. The road map of the HRB research was a "bottom-up" approach, which used hydrology research as the foundation, then moved to a more complex ecohydrology system, followed by the transport processes as the key scientific questions and the observation-measurement-simulation framework, ultimately the water resources management and regulation. This approach required an advanced scientific framework based on interdisciplinary linkages between various complementary sciences. Throughout the study progress, high-quality data and publications have been produced and attracted attention from the scientific communities around the world. Most of the data with citations can be accessed from the project study website (http://westdc.westgis.ac.cn/).

Nine papers comprise this special issue, spanning a variety of topics, from observation, numerical modeling, to data analysis and complexity theory. To adequately analyze these available data and data to be further collected in future, Gao et al. (2019) presented a perspective from complexity theory and applying it to some variables collected at the HRB to determine diurnal cycle and fractal properties. Air temperature (AT) is a subsystem of a complex climate. Long-range correlation (LRC) is an important feature of complexity. Yang et al. (2019) attempted to evaluate AT's complexity differences in different land-use types in the HRB based on the stability and LRC. Soil temperature (ST) is a critical soil variable that could affect a series of physical, chemical and biological soil processes. To measure the temporal variation and spatial pattern of ST fluctuation in the Babao River Basin. Ning et al. (2019) analyzed the fluctuation of ST at various depths with ST data at 4-, 10-, and 20-cm depths using classical statistical methods and permutation entropy. The analysis of the soil moisture evolution trend and the influence of different radiations on soil moisture is of great significance to the simulation and prediction of soil moisture. Zhang et al. (2019) utilized 
soil moisture (2-60 cm) and various radiation data from 2014-2015 at A'rou superstation and applied adaptive fractal analysis (AFA) to analyze long range correlation (LRC) of soil moisture and long-range cross correlation (LRCC) between moisture and three radiations in different timescales and soil-depths. Li et al. (2019) examined the variation of Reaumuria soongorica patch structure and community spatial pattern along precipitation gradient in the middle and lower HRB, using plots data from field survey during 2014. Correspondingly, soil texture and heterogeneity in surface-soil properties (the ratio of biological soil crust (BSC) to bare gravels (BG)) were explored. Yang et al. (2019) selected six typical ecosystems, alpine meadow, coniferous forest, mountains steppe, desert, cultivated crop and riparian forest in the HRB and assumed that the rainfall partitioning process of these six ecosystems is significantly different. Gross rainfall and high temporal resolution soil water data obtained from 12 automatic observation sites were used to determine the rainfall partitioning characteristics and their influence factors. Understanding the controls on seasonal variation of energy partitioning and separation between canopy and soil surface are important for qualifying the vegetation feedback to climate system. Using a 3-year dataset of eddy covariance flux measurements of sensible and latent heat, soil heat flux, combined with energy-balanced two-source model, Wang et al. (2019) investigated energy partitioning across six typical ecosystems in the HRB. Finally, the HRB is known as a typical ecologically fragile area in the arid/semi-arid regions of northwestern China. Yuan et al. (2019) used MODIS-NDVI data with a 250-m resolution as a proxy for the terrestrial ecosystem, combined with environmental factors, to explore the spatial features of NDVI and identify the factors influencing the NDVI distribution in the HRB during the period of 2000-2016. A geographical detector (Geodetector) was employed to explore the factors that could potentially influence the NDVI distribution in the whole basin and sub-basins. In parallel, land use and cover change (LUCC) is an important indicator of the human-earth system under climate/environment change, which also serves as a key impact factor of carbon balance, and a major source/sink of soil carbon cycles. Tong et al. (2019) performed a meta-analysis to assess the response of soil organic carbon (SOC) and total Nitrogen (TN) storage to the LUCC as well as method bias based on 383 sets of SOC data and 148 sets of TN data from the HRB.

In summary, the success of the HRB study that focused on the typical representative basin in the inland river basin of arid area affected by Qilian Mountains significantly propelled the integration of watershed-scale observation-data and ecological-hydrological models, leading to an innovative combination of "natural process" and "social learning", which has promoted the scientific research of watershed beyond China. To meet the major national and local needs, a better decision support system for watershed sustainable development has also been constructed. Nevertheless, the group decision-making process of various stakeholders, such as government, experts and local residents, has not yet been integrated into the system. Therefore, future funding of the HRB research will focus on the improvement of the current observatories, models and data platforms, and decision-making support system, which aims to support the associated research in the HRB, the Qilian mountainous regions, the arid/semi-arid area in Northwest China and ultimately to the pan-Third Pole region. 


\section{Acknowledgment}

We would like to thank the high-performance computing support from the Center for Geodata and Analysis, Faculty of Geographical Science, Beijing Normal University [https:// gda.bnu.edu.cn/].

\section{References}

Gao J B, Fang P, Yuan L H, 2019. Analyses of geographical observations in the Heihe River Basin: Perspectives from complexity theory. Journal of Geographical Sciences, 29(9): 1441-1461.

Li X, Cheng G D, Ge Y C et al., 2018. Hydrological cycle in the Heihe Riber Basin and its implication for water resource management in Endorheic Basins. Journal of Geophysical Research: Atmospheres, 123: 890-914. doi: 10.1002/2017JD027889.

Li X, Cheng G D, Liu S M et al., 2013. Heihe Watershed Allied Telemetry Experimental Research (HiWATER): Scientific objectives and experimental design. Bulletin of the American Meteorological Society, 94(8): 1145-1160. doi: 10.1175/BAMS-D-12-00154.1.

Li X, Li X W, Li Z Y et al., 2009. Watershed allied telemetry experimental research. Journal of Geophysical Research: Atmospheres, 114: 2191-2196. doi: 10.1029/2008JD011590.

Li X, Liu S M, Xiao Q et al., 2017. A multiscale dataset for understanding complex eco-hydrological processes in a heterogeneous oasis system. Scientific Data, 4: 170083. doi: 10.1038/sdata.2017.83.

Li W, Li X Y, Huang Y M et al., 2019. Spatial patch structure and adaptive strategy for desert shrub of Reaumuria soongorica in arid ecosystem of the Heihe River Basin. Journal of Geographical Sciences, 29(9): 1507-1526.

Liu S M, Li X, Xu Z W et al., 2018. The Heihe integrated observatory network: A basin-scale land surface processes observatory in China. Vadose Zone Journal, 17: 180072. doi: 10.2136/vzj2018.04.0072.

Ning L X, Cheng C X, Shen S, 2019. Spatial-temporal variability of the fluctuation of soil temperature in the Babao River Basin, Northwest China. Journal of Geographical Sciences, 29(9): 1475-1490.

Song C Q, Yuan L H, Yang X F et al., 2017. Ecological-hydrological processes in arid environment: Past, present and future. Journal of Geographical Sciences, 27(12): 1577-1594.

Tong J H, Hu J H, Lu Z et al., 2019. The impact of land use and cover change on soil organic carbon and total nitrogen storage in the Heihe River Basin: A meta-analysis. Journal of Geographical Sciences, 29(9): $1578-1594$.

Wang P, Li X Y, Tong Y Q et al., 2019. Vegetation dynamics dominate the energy flux partitioning across typical ecosystem in the Heihe River Basin: Observation with numerical modeling. Journal of Geographical Sciences, 29(9): 1565-1577.

Yang C Y, Huang Y M, Li E G et al., 2019. Rainfall interception of typical ecosystems in the Heihe River Basin: Based on high temporal resolution soil moisture data. Journal of Geographical Sciences, 29(9): 1527-1547.

Yang J, Su K, Ye S J, 2019. Stability and long-range correlation of air temperature in the Heihe River Basin. Journal of Geographical Sciences, 29(9): 1462-1474.

Yuan L H, Chen X Q, Wang X Y et al., 2019. Spatial associations between NDVI and environmental factors in the Heihe River Basin. Journal of Geographical Sciences, 29(9): 1548-1564.

Zhang T, Shen S, Cheng C X, 2019. Impact of radiations on the long-range correlation of soil moisture: A case study of the A'rou superstation in the Heihe River Basin. Journal of Geographical Sciences, 29(9): 1491-1506. 